\title{
Enhanced Invasive Weed Optimization Algorithm with Chaos Theory for Weightage based Combined Economic Emission Dispatch
}

\section{Sadashiv Halbhavi B}

Electrical and Electronics Engineering KLS Vishwanathrao Rural Institute of Technology Haliyal, Karnataka, India

sadashivhalbhavi1989@gmail.com

\section{Ambekar S K}

Vasantrao Potdar Polytechnic

Belgaum, Karnataka, India

\author{
Kodad S F \\ Electrical \& Electronics Engineering \\ PES Institute of Technology and Management \\ Shivamogga, Karnataka, India \\ Manjunath D \\ KLS Vishwanathrao Rural Institute of Technology \\ Haliyal, Karnataka, India
}

\begin{abstract}
Recently, electric power networks include diverse renewable energy resources, with the fast progress of advancements. In this case, the optimal Economic Dispatch (ED) is necessary by the power system because of the increase of power generation cost and yet rising demand for electrical energy. Hence, the minimization of power generation costs regarding the emission cost and fuel cost has to turn out to be one of the major concerns in the power system. Consequently, the Enhanced Invasive Weed Optimization with chaos theory (EIWO-CT) method to give an outstanding solution for the issues about Combined Economic Emission Dispatch (CEED) is proposed in this paper. It examines the sturdiness of the developed method in six Hybrid Renewable Energy Systems (HRES) test bus systems that integrate the wind turbine beside the thermal power plant. Subsequently, this work simulates an important convergence analysis and the validation for the quality of CEED by the EIWO-CT method. Finally, the results analyzed with four existing methods such as Genetic Algorithm (GA), Particle Swarm Optimization (PSO) and Grey Wolf Optimization (GWO) to confirm the effectiveness of the developed method regarding the emission cost and fuel cost minimization.
\end{abstract}

Keywords: Economic Dispatch; Power System; electrical energy; fuel cost; Emission Cost

\begin{tabular}{ll} 
Nomenclature & \\
\hline Abbreviations & Descriptions \\
\hline ELD & Economic Load Dispatch \\
GA & Genetic Algorithm \\
eFPA & Euclidean Affine Flower Pollination Algorithm \\
ABC & Artificial Bee Colony Optimization \\
EmD & Emission Dispatch \\
BSA & Backtracking Search Algorithm \\
PSO & Particle Swarm Optimization \\
DHSA & Differential Harmony Search Algorithm \\
ED & Economic Dispatch \\
MSSA & Modified Social Spider Algorithm \\
MHS & Modified HS \\
DE & Differential Evolution \\
DEED & Dynamic Economic and Emission Dispatch \\
PV & Photo Voltaic \\
GSO & Group Search Optimizer \\
CPF & Carbon Price Floor \\
SOA & Seeker Optimization Algorithm \\
EPS & Emission Performance Standard \\
DWPSO & Double-Weighted PSO \\
EMR & Electricity Market Reform \\
BA & Bat Algorithm \\
SD & Standard Deviation \\
IA & Immune Algorithm \\
BFPA & Binary Flower Pollination Algorithm \\
CEED & Combined Economic and Emission Dispatch \\
\hline
\end{tabular}

(C) Resbee Publishers

https://doi.org/10.46253/jcmps.v2i3.a3 


\section{Introduction}

A power system is developed from generator sites in order to encourage electric energy to a few regions taking into consideration a sharing measure of a total power to fulfill a load demand at a specific period time of operation [7]. The main reason for this scheme is to reduce the total technical operating cost via the amalgamation of several kinds of power plants. A decreasing cost issue of the power system operation can be articulated by utilizing an ELD in order to attain the least total fuel cost of generating units [6]. Generally, at a definite time, the main purpose of ELD's is to schedule the committed generating unit outputs in order to fulfill a specific load demand in a few operational constraints [1]. Currently, as the public awareness of environmental protection is augmented to minimize atmospheric emissions, at thermal power plants, the ELD considers pollutant emissions in the air from combustions of fossil fuels [8]. An EmD is considered, the power system operation needs to adjust operational schemes of the thermal power plants in order to reduce pollutants in the air [5]. To keep away from complexity issues of both dispatching kinds in order to determine the solutions with different targets, EMD and ELD are distorted into the single objective function as a CEED.

ED is the main issue associated with the operation of islanded microgrids or grid associated. For different generating units in the system, ED is the determination of the active power output to achieve the objective model when fulfilling diverse constraints [4]. To create the microgrids an additional probable and sensible substitute to the existing power systems, inventive management methods should be used to deal with the environmental constraints and dynamic behavior of these microgrids [26] [27].

The purpose of the ED issue is to search for the best schedule for all dedicated generators to reduce the operating fuel cost whereas fulfilling all types of constraints like balance and load constraint and generation capacity constraints in power systems [9]. On the other hand, with the rising public problem on the environmental crisis occurred by fossil fuels, it is vital for us not merely to be concerned for economic advantage, other than in addition to undertaking the emission crisis of fossil fuels [10]. As a result, the emission aspires must as well be concerned [11].

Various algorithms were presented to solve the ED crisis [12]. It is categorized into traditional optimization algorithms and Meta-heuristic based optimization algorithms. The traditional algorithms comprise of the Interior Point algorithm, Linear Programming, and Lambda Iteration algorithm works efficiently to resolve the ELD issue using convex cost functions merely and be unsuccessful to discover the global best solution of the non-convex ELD issue. The meta-heuristic method is able to resolve the global best solution of the non-convex ELD issues. The MSSA was presented to resolve the ED issue and to solve the non-convex ELD issue like GA [13], BSA [21], PSO [14], ABC [18], DE [15], Differential HSA [17], GSO [19], SOA [16], IA[20], and Hybrid HAS with arithmetic crossover operation [22]. The GA requires a great computational time.

This main contribution of this paper is to propose a solution for the minimization of fuel cost and emission cost for HRES power systems by exploiting the EIWO-CT algorithm. Finally, the implementation of the proposed method is compared with the conventional methods in the six test bus system.

\section{Literature Review}

In 2018, Ehab E. Elattar [1] presented an MHS method in order to resolve the CEED issue in the microgrid taking into consideration the wind and solar power cost functions. The proposed method was derived by not only altering the parameters but also enhancing the model and operation of the conventional HS method. The key to the CEED issue of the microgrid in view of the wind and solar power cost functions was attained for diverse cases by exploiting the MHS method and a few lately published methods.

In 2017, C. Shilaja and K. Ravi [2], addressed the challenge in sustainable and continuous power at a better cost. The augmentin cost depletion of non-renewable sources was required to exploit renewable energy resources as a substitute energy source. In order to optimize the ED issue, a novel approach was developed on the basis of the CEED for PV plants and thermal power generation units. In the CEED method to enhance the BFPA and ED, eFPA was exploited to solve the optimization issue for $20 \mathrm{PV}$ and five thermal generators were performed with complete and minimized solar radiation.

In 2019, Fangting Hu, Kevin J. Hughes et al [3], developed a new DEED algorithm to an integrated traditional and wind power system integrating the EPS and the CPF which was aided exploiting the EMR. The presented method aspires to decide the optimal operation scheme for the presented system on 
power dispatch in view of wind power waste and reserve and the environmental feature, particularly the $\mathrm{CPF}$ of greenhouse gases and the emission limit of the EPS for various de-carbonization cases.

In 2018, Huijun Lianga et al [4], proposed a multiobjective hybrid BA to resolve the integrated ED issue with power flow constraints. Here, an elitist non-dominated sorting algorithm and an enhanced crowding-distance sorting algorithm were developed to obtain a consistently distributed Pareto Optimal Front. An enhanced complete learning scheme was exploited to improve the learning capability of the population. In this manner, each individual can study not only from all individual optimal solutions but also from the global optimal solutions. An arbitrary black hole method was developed to assure each dimension in the current solution was updated individually with a predefined probability

In 2018, Mostafa Kheshti and Lei Ding [5], presented the DWPSO model to solve non-convex CEED issues with wind power penetration and to solve the non-convex multiple fuel alternative ED issue was scientifical. The results on various scenario study systems were evaluated with other published algorithms in state-of-arts and verify the efficiency of DWPSO over other conventional algorithms. DWPSO effectively minimizes the construction costs and hazardous emissions taking into account wind power penetration, chooses the optimal fuel types of the generators and alters the possible and best settings to assign load demand in the power system.

\section{CEED Model with HRES}

Consider an HRES power generation system that comprises both solar energy systems and wind turbines. Moreover, the wind turbine is considered to be WT and the total number of the solar system is considered as SS. Fundamentally, the total energy generated from the solar system $\mathrm{I}^{\mathrm{Gp}}$ is on the basis of the intensity of the solar, and generated power is within the minimum and maximum values. Therefore, the generated power is the model indicated in eq. (1) where $\mathrm{p}=1,2, \ldots . \mathrm{SS}, \eta^{\mathrm{p}}$ indicates the competence of the system, $\mathrm{S}(\mathrm{t})$ indicates the solar intensity and $\mathrm{S}^{\mathrm{p}}$ denotes the area of the system. Similarly, eq. (2) represents the total energy from the wind turbine $\mathrm{Er}^{\mathrm{w}}$ that is on the basis of the turbine speed in different areas. In Eq. (2), $\mathrm{w}=1,2, \ldots \mathrm{WT}, \mathrm{SA}$ denote the swept area, $\mathrm{AP}_{0}$ indicate the atmospheric pressure of the standard sea level $(101325 \mathrm{~Pa}), P^{E}$ denote the power coefficient of wind turbine, gc denote the gravitational constant, $\mathrm{u}_{\mathrm{w}}$ indicates the velocity of wind turbine, $\mathrm{G}$ denote the altitude in meters, $\mathrm{SP}_{\mathrm{k}}$ denote the specific gas constant of air $(287 \mathrm{~J} /(\mathrm{kg} . \mathrm{K}))$, $\mathrm{T}$ denotes the temperature in Kelvin as $\mathrm{T}=\mathrm{T}_{0}-\mathrm{RG}$ where $R$ denote the temperature lapse rate $\left(0.0065{ }^{\circ} \mathrm{C} / \mathrm{m}\right)$ and $\mathrm{T}_{0}$ denote the sea level temperature (288K).

$$
\begin{aligned}
& \mathrm{I}^{\mathrm{Gp}}=\eta^{\mathrm{p}} \mathrm{S}^{\mathrm{p}} \mathrm{S}(\mathrm{t}) \\
& \mathrm{Er}^{\mathrm{W}}=\sum_{\mathrm{w}=1}^{\mathrm{WT}} \frac{\mathrm{AP}_{0} \mathrm{SAu}_{\mathrm{w}}^{3} \mathrm{P}^{\mathrm{c}}}{2 \mathrm{SP}_{\mathrm{k}} \mathrm{T}} \mathrm{e}^{-\frac{\mathrm{gcG}}{\mathrm{SP}_{\mathrm{k}} \mathrm{T}}}
\end{aligned}
$$

\subsection{Economic Model}

Eq. (3) represents the sum of the quadratic function creates the total cost function of the fuel $\mathrm{F}\left(\mathrm{I}^{\mathrm{Gp}}\right.$ ) whereas $q^{p}$ denotes the fuel cost coefficient of the $p^{\text {th }}$ generating unit, $I^{\mathrm{Gp}}$ denote power generation of $\mathrm{p}^{\text {th }}$ generating unit, $\mathrm{k}^{\mathrm{p}}, \mathrm{l}^{\mathrm{p}}, \mathrm{n}^{\mathrm{p}}, \mathrm{o}^{\mathrm{p}}$ and $\mathrm{j}^{\mathrm{w}}$ denotes the fuel cost coefficient of $\mathrm{w}^{\text {th }}$ wind turbine system and $\mathrm{I}_{\mathrm{min}}^{\mathrm{Gp}}$ indicates the minimum active power output of the $\mathrm{p}^{\text {th }}$ generating unit.

$$
F\left(I^{G p}\right)=\sum_{p=1}^{S S}\left[p^{e}+1^{p} I^{G p}+n^{p}(I G p)^{2}+{ }_{o}^{p} \sin \left\{q^{p}\left(I_{\min }^{G p}-I^{G p}\right)\right\} \mid\right]+\sum_{w=1}^{W T} j^{w} E r^{w}
$$

\subsection{Emission Model}

Generally, the thermal power plant emits $\mathrm{NO}_{\mathrm{x}}$ or $\mathrm{SO}_{2}$ as emissions because of the burning of fuels. Here, only $\mathrm{NO}_{\mathrm{x}}$ as emissions are considered. For that reason, the sum of the quadratic function pursued using the exponential function creates the necessary emission function that is stated in eq. (4). In eq. (4), $\mathrm{u}^{\mathrm{p}}, \mathrm{v}^{\mathrm{p}}, \mathrm{w}^{\mathrm{p}}, \mathrm{x}^{\mathrm{p}}$ and $\mathrm{y}^{\mathrm{p}}$ state the coefficient of emissions regarding $\mathrm{p}^{\text {th }}$ generating unit. Nevertheless, the coefficients $\delta^{\mathrm{p}}$ and $\eta^{\mathrm{p}}$ can be exploited merely while the system is related to the valve point effect. 


$$
\mathrm{E}\left(\mathrm{I}^{\mathrm{Gp}}\right)=\sum_{\mathrm{p}=1}^{\mathrm{SS}} \mathrm{v}^{\mathrm{p}}+\mathrm{u}^{\mathrm{p}} \mathrm{I}^{\mathrm{Gp}}+\mathrm{w}^{\mathrm{p}}\left(\mathrm{I}^{\mathrm{Gp}}\right)^{2}+\mathrm{x}^{\mathrm{p}} \exp \left(\mathrm{y}^{\mathrm{p}} \mathrm{G}{ }^{\mathrm{Gp}}\right)
$$

\subsection{Power Balancing Model}

As regards the minimization procedure, it is necessary to assure a small number of equality and inequality constraints. Additionally, the equality constraint can be referred to as power balance, as it created the total power that must transport the total power demand and total power loss in the network. Eq. (5) indicates the function of the power balancing model whereas $\mathrm{P}^{\text {loss }}$ indicates the active power loss of the network and $\mathrm{P}^{\text {ld }}$ indicates the total load demand. Moreover, the formulation $\mathrm{P}^{\text {loss }}$ is stated in eq. (6) whereas $B_{p n}$ denotes the loss coefficient between $\mathrm{m}^{\text {th }}$ and $\mathrm{n}^{\text {th }}$ generating units.

$$
\begin{aligned}
& \sum_{\mathrm{p}=1}^{\mathrm{SS}} \mathrm{I}^{\mathrm{Gm}}-\mathrm{P}^{\mathrm{ld}}-\mathrm{P}^{\mathrm{loss}}=0 \\
& \mathrm{P}^{\mathrm{loss}}=\sum_{\mathrm{p}=1}^{\mathrm{N}} \sum_{\mathrm{n}}^{\mathrm{N}} \mathrm{I}^{\mathrm{Gp}} \mathrm{B}_{\mathrm{pn}} \mathrm{I}^{\mathrm{Gn}}
\end{aligned}
$$

\section{Proposed Methodology EIWO-CT for CEED Model}

\subsection{Objective Function}

The amalgamation of two self-reliant objectives can able to resolve the CEED issue. Those objectives are related to the emission cost and fuel cost. For that reason, from the bi-objective model, a single objective is produced, from that; the aforesaid cost is produced by exploiting a penalty factor. Therefore, to resolve the CEED issue, it is necessary to minimize the emission cost and fuel cost. Eq. (7) states the minimization of CEED issue as a single objective function, whereas $f_{m}$ denotes the penalty factor that is stated in eq. (9), whereas $\mathrm{I}_{\max }^{\mathrm{Gp}}$ and $\mathrm{I}_{\min }^{\mathrm{Gp}}$ indicates the maximum and minimum active power output.

$$
\begin{aligned}
& \operatorname{Minimize}\left(\mathrm{F}^{\mathrm{CEED}}\right)=\mathrm{F}+\mathrm{f}_{\mathrm{m}} \mathrm{E} \\
& \operatorname{Minimize}\left(F^{C E E D}\right)=\sum_{n=1}^{S S}\left[k^{n}+1^{n} I^{G p}+n^{p}\left(I^{G p}\right)^{2}+\left|o^{p} \sin \left\{q^{p}\left(I_{\min }^{G p}-I^{G p}\right)\right\}\right|\right]+ \\
& \sum_{w=1}^{W T} \frac{P_{0} S A u_{w}^{3} P^{e}}{2 S_{k} T} e^{-\frac{g H}{G_{k} T}}+f_{p}\left(\sum_{m=1}^{N G} v^{p^{2}}+u^{p_{I} G p}+{ }_{w}^{p}\left(I^{G p}\right)^{2}+x^{p} \exp \left(y^{p_{I} G p}\right)\right) \\
& f_{p}=\frac{F\left(P_{\max }^{g p}\right)}{E\left(P_{\max }^{g p}\right)} \\
& f_{p}=\frac{k^{p}+1^{p} I_{\text {max }}^{g p}+n^{p}\left(I_{\text {max }}^{g p}\right)^{2}+\left|{ }^{p} \sin \left\{q^{p}\left(I_{\text {min }}^{G p}-I_{\text {max }}^{g p}\right)\right\}\right|}{v^{p}+u^{p} I_{\text {max }}^{p m}+w^{p}\left(I_{\text {max }}^{g p}\right)^{2}+x^{p} \exp \left(y^{p} I_{\text {max }}^{g p}\right)}
\end{aligned}
$$

\subsection{Conventional IWOA}

This IWOA is a population-based optimization method, which discovers the common best of a mathematical model by emulating compatibility and arbitrariness of the weeds colony [23].

Generally, weeds are dominant herbs and its odious growth habits are a severe hazard to crops. Moreover, it has demonstrated to be adaptable and opposed to environmental alters. Hence, taking into consideration of their characteristics, an influential optimization method is attained. This method attempts to emulate adaptability, resistance, and arbitrariness of a weed community in a sample [24].

This algorithm is enthused using a phenomenon in agriculture known colonies of invasive weeds. In accordance with a widespread description, weed is a plant that grows inadvertently. Even though weeds might have a lot of exploits and advantages in a few areas, if a similar plant grows in an area that obstructs human' requirements and activities, it is termed a weed. In [23], a simple numerical optimization method was presented that is on the basis of the colonized weed termed the Invasive Weed Optimization Algorithm. This method is easy however effectual in convergence to optimal solutions by exploiting fundamental features like growth, seeding, and rivalry in a weed colony. 
To imitate the habitat behavior of weeds, a few fundamental descriptions of the procedure are contemplated as below:

a) The initialization of primary population initialization, in the search space, a restricted number of seeds is distributed.

b) In reproduction, every seed grows into a flowering plant and generates seeds which are depending on their fitness value. The number of grains of grasses minimizes linearly from $E_{\max }$ to $E_{\min }$, $E_{\max }$ represents the maximum number of seeds, and $E_{\min }$ represents the minimum number of seeds.

$$
\mathrm{n}\left(\mathrm{w}_{\mathrm{i}}\right)=\frac{\mathrm{E}_{\max }\left(\max _{\mathrm{fit}}-\mathrm{fit}\left(\mathrm{w}_{\mathrm{i}}\right)\right)+\mathrm{E}_{\min }\left(\mathrm{fit}_{\mathrm{it}}\left(\mathrm{w}_{\mathrm{i}}\right)-\min _{\mathrm{fit}}\right)}{\max _{\text {fit }}-\min _{\text {fit }}}
$$

c) In Spectral Spread, the seeds formed using the collection in the normal distribution with a mean planting location and SD is generated using the eq. (12).

$$
\delta_{\mathrm{t}}=\left(\frac{\mathrm{T}-\mathrm{t}}{\mathrm{T}}\right)^{\mathrm{n}}\left(\delta_{\text {initial }}-\delta_{\text {final }}\right)+\delta_{\text {final }}
$$

In eq. (12), $\mathrm{T}$ indicates the number of maximum iterations, $\delta_{\mathrm{t}}$ indicates the current standard deviation and $\mathrm{n}$ indicates the nonlinear modulation index, $\delta_{\text {initial }}$ indicates the basic standard deviation and $\delta_{\text {final }}$ indicates the final standard deviation.

This adaptation confirms so as to drop of grain in the range minimizes nonlinearly at every step, foremost to additional healthy plants and eradicating unsuitable plants, and exhibits the transport mode from $r$ to selection of $\mathrm{K}$.

d) Competitive deprivation: In the colony $\left(\mathrm{Q}_{\max }\right)$, which represents the maximum population, if the numbers of grasses go beyond the utmost numbers of grasses, the grass with most horrible fitness is eradicated from the colony in order that constant numbers of herbs have stayed in the colony.

e) This procedure maintains until the utmost number of iterations is attained, and after that the least colony cost function of the grasses is saved.

\subsection{Proposed Enhanced IWOA-CT}

The Optimization methods on the basis of the chaos theory exploit stochastic search algorithms. These methods are diverse from developing a reasonable method and intelligent population on the basis of the methods [25].

Because of the non-repetitive nature of chaos theory, it does the global searches at an earlier rate than accidental searches which are associated with the probabilities. Additionally, population diversity must be improved. It is also assured that our member's population wraps the complete search area. Therefore, optimal or close to optimal responses will be among the population.

One of the renowned chaotic maps represents the logistic chaotic map. This model is a second-order polynomial and the map is stated in eq. (13).

$$
\mathrm{y}_{\mathrm{j}+1}=\text { by }_{\mathrm{j}}\left(1-\mathrm{y}_{\mathrm{j}}\right) \text { for } 0<\mathrm{b} \leq 4, \mathrm{j}=0,1,2, \ldots . . \mathrm{y}_{\mathrm{j}} \in[0,1]
$$

In eq. (13), $\mathrm{y}_{0}$ indicates the initial value of the function and $\mathrm{y}_{\mathrm{n}}$ indicates the value of the function subsequent to $\mathrm{n}^{\text {th }}$ iteration. To create this equation demonstrate a chaotic behavior, $\eta$ must be set to 4 . The preliminary circumstances have to be within the range of $(1,0)$. So that $y_{n} \neq\{0,0.25,0.5,0.75\}$.

The instant method to recover the invasive weed algorithm is to employ chaotic mapping to update the SD formula and it is stated in the eq. (14).

$$
\delta_{\mathrm{t}}=\left(\frac{\mathrm{T}-\mathrm{t}}{\mathrm{T}}\right)^{\mathrm{n}}\left(\delta_{\text {initial }}-\delta_{\text {final }}\right)+\delta_{\text {final }} \times \mathrm{x}(\mathrm{t})
$$

In eq. (14), $\mathrm{x}(\mathrm{t})$ can be corresponding to chaotic mapping in the $\mathrm{t}^{\text {th }}$ iteration.

In this algorithm, most excellent weed can be exploited to go the residual weeds to the optimal location.

Hence, another formulation is presented and stated in eq. (15).

$$
\mathrm{x}_{\mathrm{i}}^{\mathrm{t}+1}=\delta(\mathrm{t}) \times \mathrm{y}_{\mathrm{i}}^{\mathrm{t}}+\left(\mathrm{y}_{\text {best }}-\mathrm{y}_{\mathrm{i}}^{\mathrm{t}}\right)
$$

In eq. (15), it is the novel weed location in $\mathrm{t}^{\text {th }}$ iteration. $\mathrm{y}_{\text {best }}$ indicate the optimal weed establish in the complete population. In eq. (15) the novel location is updated by exploiting the previous location and the difference among previous location and the optimal location in the SD. After that, these novel circumstances are also validated in the method. 
This equation enhances the global and local search methods, due to the SD plays the task of equilibrium in global and local searches. Fig 1 demonstrates the flowchart of the proposed Enhanced Invasive Weed Optimization algorithm with chaos Theory methodology.

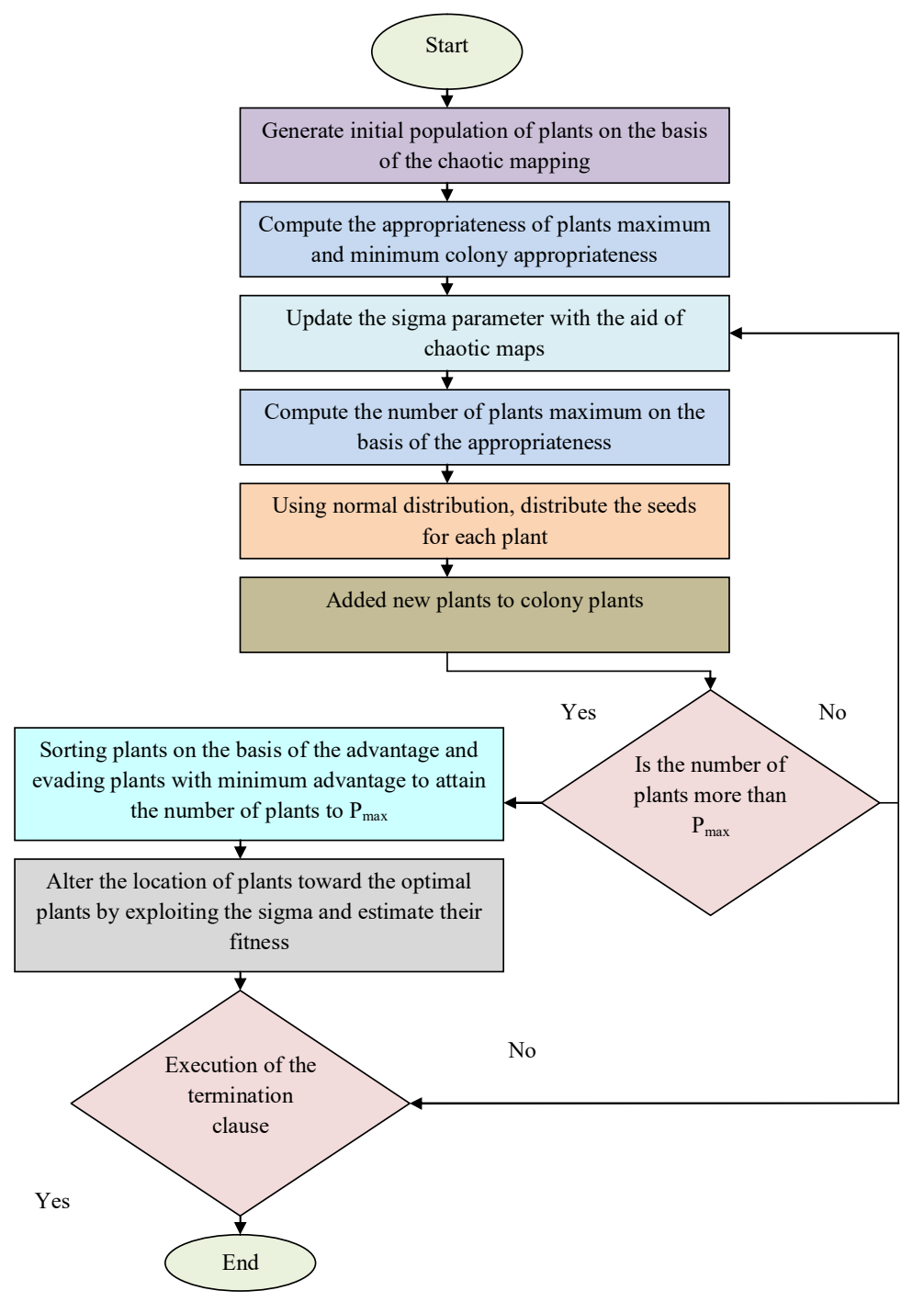

Fig. 1. Flowchart of the proposed Enhanced Invasive Weed Optimization algorithm with chaos Theory

\section{Results and Discussions}

\subsection{Simulation Set up}

The simulation concerning the minimization of the CEED problem was evaluated in 6 HRES test bus systems. These systems were broadly exploited as benchmarks in the area of electrical power systems for the reason of CEED issue minimization that hence was exploited by various research groups throughout the worldwide. The configuration of each test system was demonstrated in Fig. 2, 3, 4, 5, 6, and 7, and the load demand of every test system indicated in the Gaussian distribution function. Then, the necessary demonstration concerning the six HRES test bus systems is stated as follows:

\subsection{Performance Analysis}

The convergence analysis of the proposed EIWOA-CT in minimizing the fuel cost and emission cost of 6 HRES test systems is demonstrated in Fig. 2, 3, 4, 5, 6 and 7. This analysis evaluates the proposed method with existing methods such as GA, GWO and PSO. The number of analysis is supposed to be 1000. For that reason, the convergence concerning the experimentation is related to the minimization function, as it requirements to minimize the emission cost and fuel cost of the thermal power plant. In Fig. 2, the convergence analysis of test system 1 where the PSO method obtains maximum cost function 
and the proposed method obtains the minimization cost function till the 1000 iterations. Moreover, the convergence analysis of test system 2 where the proposed create the minimization cost functions is one step minimum than the PSO method in Fig 3. The overall analysis states the convergence analysis shows the dominance of the proposed method in minimizing the fuel cost and emission cost of the thermal units in Fig 4, 5, 6 and 7.

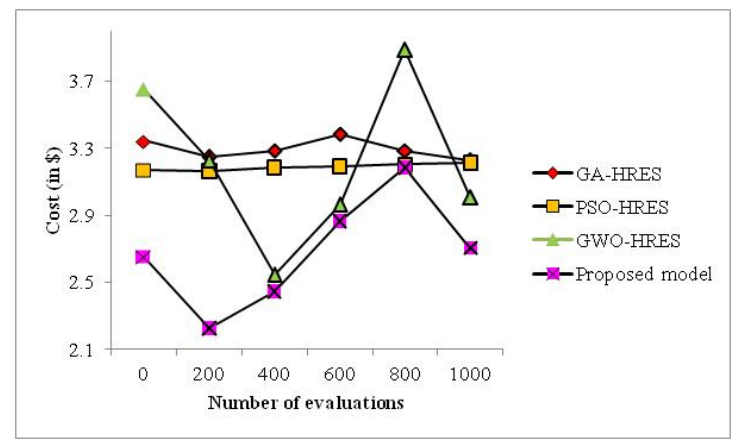

Fig. 2. Analysis of the proposed method in Test bus system 1

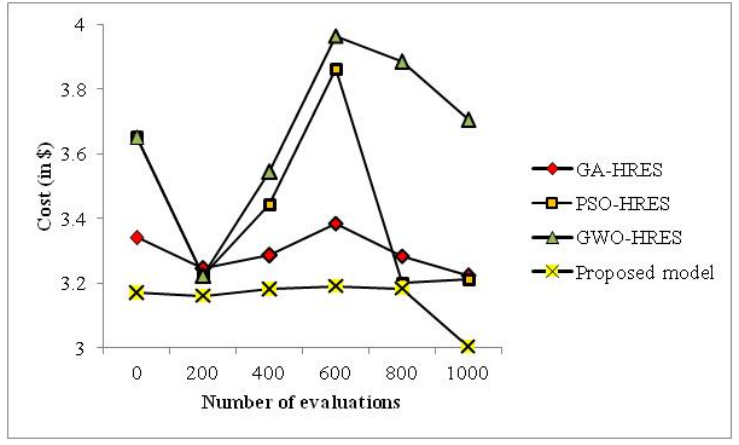

Fig. 3. Analysis of the proposed method in Test bus system 2

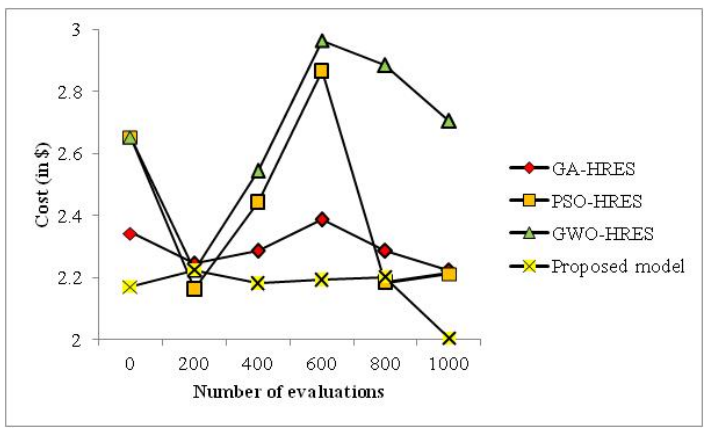

Fig. 4. Analysis of the proposed method in Test bus system 3

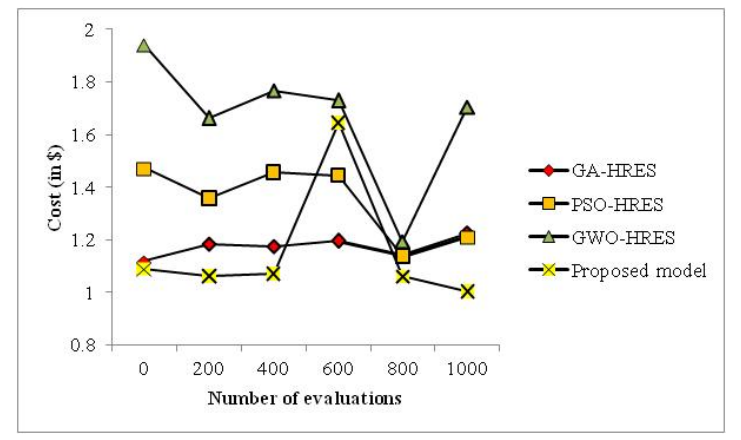

Fig. 5. Analysis of the proposed method in Test bus system 4 


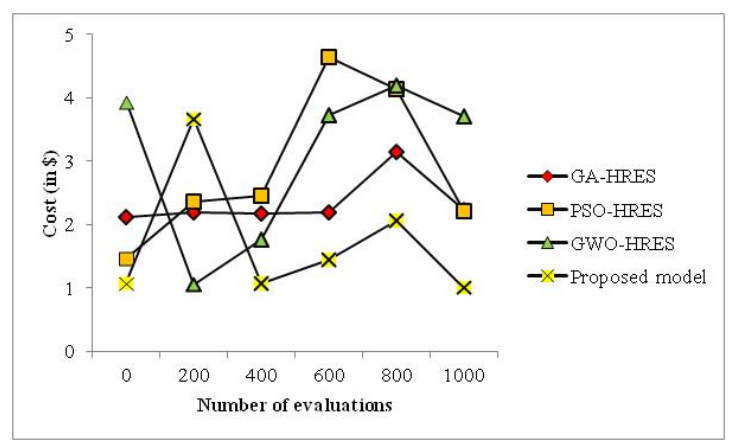

Fig. 6. Analysis of the proposed method in Test bus system 5

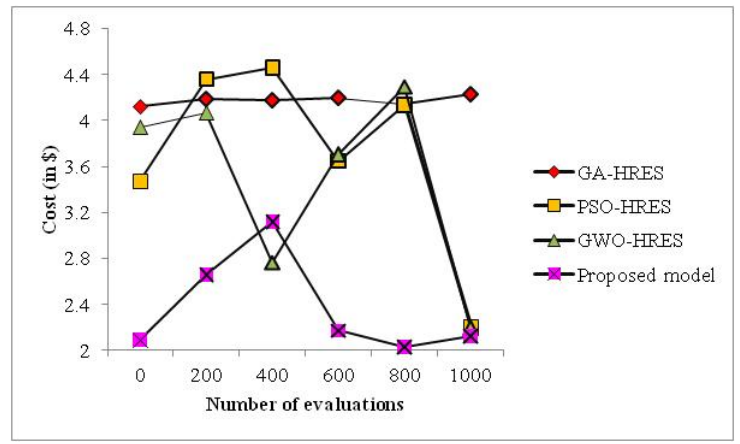

Fig. 7. Analysis of the proposed method in Test bus system 6

\section{Conclusion}

The feature related to the energy planning environment was a crucial investigation area for the control and operation of the power systems. The minimization of emissions and fuel cost has considered as the main concern in the present years in all power systems. In this paper, the validation that uses the suitable CEED model was conferred in the power system. For that reason, it was integrated the wind turbine to the subsequently of the thermal power plant to extend the CEED performance. Here, EIWOCT algorithm was developed in order to resolve the CEED issues; and it was performed in six HRES test bus system. Then, it was evaluated to analyze the proposed algorithm with the conventional GA, GWO and PSO algorithms, to verify its performance. In addition, probable convergence analysis and the verification concerning the quality of CEED was stated. Additionally, the results were exhibited by the proposed EIWO-CT algorithm have well sustained to minimize the fuel cost and emission cost of the power systems.

\section{Compliance with Ethical Standards}

Conflicts of interest: Authors declared that they have no conflict of interest.

Human participants: The conducted research follows the ethical standards and the authors ensured that they have not conducted any studies with human participants or animals.

\section{References}

[1] Ehab E. Elattar,"Modified harmony search algorithm for combined economic emission dispatch of microgrid incorporating renewable sources",Energy, Volume 159, 15 September 2018, Pages 496-507.

[2] C. Shilaja, K. Ravi,"Optimization of emission/economic dispatch using euclidean affine flower pollination algorithm (eFPA) and binary FPA (BFPA) in solar photo voltaic generation",Renewable Energy, Volume 107, July 2017, Pages 550-566.

[3] Fangting Hu, Kevin J. Hughes, Derek B. Ingham, Lin Ma, Mohamed Pourkashanian,"Dynamic economic and emission dispatch model considering wind power under Energy Market Reform: A case study", International Journal of Electrical Power \& Energy Systems, Volume 110, September 2019, Pages 184-196. 
[4] Huijun Liang, Yungang Liu, Fengzhong Li, Yanjun Shen," A multiobjective hybrid bat algorithm for combined economic/emission dispatch", International Journal of Electrical Power \& Energy Systems, Volume 101, October 2018, Pages 103-115.

[5] Mostafa Kheshti, Lei Ding, Shicong Ma, Bing Zhao," Double weighted particle swarm optimization to non-convex wind penetrated emission/economic dispatch and multiple fuel option systems", Renewable Energy, Volume 125, September 2018, Pages 1021-1037.

[6] K.K. Mandal, S. Mandal, B. Bhattacharya, N. Chakraborty, "Non-convex emission constrained economic dispatch using a new self-adaptive particle swarm optimization technique", Applied Soft Computing, Vol. 28, pp. 188-195, March 2015.

[7] Vinay Kumar Jadoun, Nikhil Gupta, K.R. Niazi, Anil Swarnkar, "Modulated particle swarm optimization for economic emission dispatch", International Journal of Electrical Power \& Energy Systems, Vol. 73, pp. 80-88, December 2015.

[8] Shanhe Jiang, Zhicheng Ji, Yan Wang, "A novel gravitational acceleration enhanced particle swarm optimization algorithm for wind-thermal economic emission dispatch problem considering wind power availability", Electrical Power and Energy Systems, Vol. 73, pp. 1035-1050, 2015.

[9] A.Y. Abdelaziz, E.S. Ali, S.M. Abd Elazim, "Combined economic and emission dispatch solution using Flower Pollination Algorithm", Electrical Power and Energy Systems, Vol. 80, pp. 264-274, 2016.

[10] N. A. Khan, G. A. S. Sidhu and F. Gao, "Optimizing Combined Emission Economic Dispatch for Solar Integrated Power Systems," in IEEE Access, vol. 4, pp. 3340-3348, 2016.

[11] Pratyush Das, Raju Patwary and S.C. Konar, "Combined Economic And Emission Dispatch With And Without Considering Transmission Loss", Computer Science \& Information Technology, pp. 347-355, 2013.

[12] U. Guvenca, Y. Sonmez, S. Duman, N. Yorukeren,"Combined economic and emission dispatch solution using gravitational search algorithm", Sharif University of Technology, Vol. 19, no. 6, pp. 1754-1762, 2012.

[13] D.C. Walters, G.B. Sheble, Genetic algorithm solution of economic dispatch with valve point loading, IEEE Trans. Power Syst. 8 (1993) 1325e1332.

[14] Z.-L. Gaing, Particle swarm optimization to solving the economic dispatch considering the generator constraints, IEEE Trans. Power Syst. 18 (2003).

[15] N. Noman, H. Iba, Differential evolution for economic load dispatch problems,Electr. Power Syst. Res. 78 (2008) 1322e1331, .

[16] B. Shaw, V. Mukherjee, S.P. Ghoshal, Seeker optimisation algorithm: application to the solution of economic load dispatch problems, IET Gener. Transm.Distrib. 5 (2011) 81.

[17] D.C. Secui, The chaotic global best artificial bee colony algorithm for the multiarea economic/emission dispatch, Energy 93 (2015) $2518 \mathrm{e} 2545$.

[18] M. Moradi-Dalvand, B. Mohammadi-Ivatloo, A. Najafi, A. Rabiee, Continuous quick group search optimizer for solving non-convex economic dispatch problems, Electr. Power Syst. Res. 93 (2012) 93e105.

[19] V.S. Arag on, S.C. Esquivel, C.A. Coello Coello, An immune algorithm with power redistribution for solving economic dispatch problems, Inf. Sci. (Ny) 295 (2015) 609e632.

[20] M. Modiri-Delshad, N.A. Rahim, Solving non-convex economic dispatch problem via backtracking search algorithm, Energy 77 (2014).

[21] A. Gupta, P.K. Padhy, Modified firefly algorithm based controller design for integrating and unstable delay processes, Eng. Sci. Technol. Int. J. 19 (2016).

[22] P.C. Pradhan, R.K. Sahu, S. Panda, Firefly algorithm optimized fuzzy PID controller for AGC of multi-area multi-source power systems with UPFC and SMES, Eng. Sci. Technol. Int. J. 19 (2016).

[23] A. R. Mehrabian, C. Lucas, 2006. A novel numerical optimization algorithm inspired from weed colonization. Ecol. Inf. 1 (4), 355-366.

[24] H. Hajimirsadeghi, A. Ghazanfari, A. Rahimi-Kian \& C. Lucas. (2009). Cooperative coevolutionary invasive weed optimization and its application to Nash equilibrium search in electricity markets. In World Congress on Nature and Biologically Inspired Computing (NaBIC), (pp. 1532-1535).

[25] R. Kumar Mandava, P. R. Vundavili. (2018) Implementation of modified chaotic invasive weed optimization algorithm for optimizing the PID controller of the biped robot. Indian Academy of Sciences. Sådhanå (2018) 43:66.

[26] Naresh Kumar Yadav,"Optimal ATC Enhancement Model: Analysis of the Effect of Thyristor-Controlled Series Compensation",, Volume 2, Issue 2, January 2019.

[27] Shilpa S. Shrawane Kapse,Dr. Manoj B. Daigavane and Dr. Prema M. Daigavane,"Localization and Sizing of UPFC: A Hybrid Optimization Algorithm for Solving Reactive Power Dispatch",Journal of Computational Mechanics, Power System and Control (JCMPS), Volume 2, Issue 2, January 2019. 